\title{
Anabases
}

ANABASES Traditions et réceptions de l'Antiquité

$14 \mid 2011$

Varia

\section{Bibliographie générale}

\section{(2) OpenEdition}

1 Journals

Édition électronique

URL : http://journals.openedition.org/anabases/2316

DOI : 10.4000/anabases.2316

ISSN : 2256-9421

\section{Éditeur}

E.R.A.S.M.E.

\section{Édition imprimée}

Date de publication : 1 octobre 2011

Pagination : 133-138

ISSN : 1774-4296

\section{Référence électronique}

«Bibliographie générale », Anabases [En ligne], 14 | 2011, mis en ligne le 01 octobre 2014, consulté le

21 octobre 2019. URL : http://journals.openedition.org/anabases/2316 ; DOI : 10.4000/anabases. 2316

(c) Anabases 
Anabases 14 (2011), p. 133-138.

\section{Bibliographie générale}

Acosta, J. (DE). De Novi Orbis natura et ratione, in Th. DE BRY (et fils), Americae nona \& postrema pars, Francfort, 1602.

Aristote. Poétique, R. Dupont-Roc et J. Lallot (éd.), Paris, Seuil, 1980.

Artaud, N.-L.-M. Théâtre des Grecs. Comédies d'Aristophane, Brissot-Thivars 1830.

—, Comédies d'Aristophane, Paris, Charpentier, 1841.

Artaud de Montor, A. Fr. (sous la dir. de). Encyclopédie des gens du monde, répertoire universel des sciences, des lettres et des arts : avec des notices sur les principales familles historiques et sur les personnages célèbres, morts et vivans, par une société de savans, de littérateurs et d'artistes, français et étrangers, Paris, Treuttel et Würtz, 1833-1844, 22 vol.

Avlami, Chr. "La construcción de la Antigüedad grecorromana en la Europa de los siglos XVIII y XIX ", in M. Romero Recio, J. Alvar, Chr. Avlami (éds.), Transferencias culturales e Historiografía de la Antigüedad (t. 2), Revista de historiografia 7 (2007), p. 14-21.

-, "Civilisation versus civitas? La cité grecque à l'épreuve de la civilisation ", Revue de Synthèse 129 (2008), p. 23-56.

Baby, H. (éd.). D’Aubignac. La pratique du théâtre, Paris, Champion, 2001.

Barbier, Fr. ; Juratic, S. et Mellerio, A. Dictionnaire des imprimeurs, libraires et gens du livre à Paris (1701-1789), t. 1 (seul paru : lettres A-C), Genève, Slatkine, 2007.

BARnEsius, J. Euripidis tragæediae, fragmenta, epistolae, Cambridge, 1694.

Bastin-Hammou, M. "Anne Dacier et les premières traductions françaises d'Aristophane : l'invention du métier de femme philologue ", Littératures classiques 72 (2010), p. 85-99. 
—, "La réception française des Nuées d'Aristophane : quelques jalons " in CUsSET, Chr. et NoËL, M.-P., Contribution à l'étude des Nuées d'Aristophane, Cahiers du Groupe Interdisciplinaire de Théatre Antique, à paraître en 2011.

BAYLE, P. Dictionnaire historique et critique, Rotterdam, Leers, 1695-1697, 5édition revue, corrigée et augmentée, 4 vol., Amsterdam, P. Brunel, 1740, Genève, Slatkine reprints, 1995.

Bolleau, N. Art poétique (Thierry, Paris, 1674), Euvres de Boileau Despréaux, Didot, Paris, 1800.

BoIndin, N. Discours sur la forme et la construction du théâtre des anciens, in Mémoires de l'Académie des inscriptions, 1712, t. I, 2 p. 138.

Boindin, N. Mémoire sur les masques, in Mémoires de l'Académie des inscriptions, 1712, t. IV, p. 132.

Le Théâtre des Grecs, par le R. P. Brumoy, de la Compagnie de Jésus, à Paris, chez Rollin Père, Jean-Baptiste Coignard et Rollin fils, 1730.

—, Le Théâtre des Grecs, Aux dépens de la Compagnie de Jésus, Amsterdam, in-8, 1732.

—, Lettres du P. Brumoy au marquis de Caumont, éd. J.-M. Prat, Paris, Julien, Lasnier, Cosnard et Cie, 1857.

—, Discours sur les spectacles (1733), trad. du De theatro de Ch. Porée, éd. É. Flamarion, Toulouse, Société de Littératures Classiques, 2000.

Lennox, Ch. (translated by). The Greek Theatre of father Brumoy, London, printed for Milar, 1759.

Cappelletti, S. Luigi Riccoboni et la riforma del teatro. Dalla commedia dell'arte alla commedia borghese, Ravenna, Longo, 1986.

Chantalat, C. À la recherche du goût classique, Paris, Klincksieck, 1992.

ChARDIn, J. Voyages de Monsieur le chevalier Chardin en Perse et autres lieux de l'Orient Première partie, Amsterdam, 1686 (édition intégrale, en 3 volumes, Amsterdam, 1711).

[COYER, G.-Fr.]. Discours sur la satyre contre les Philosophes, représentée par une Troupe qu'un Poëte Philosophe fait vivre, \& approuvée par un Académicien qui a des Philosophes pour Collégues, À Athènes, chez le Libraire anti-Philosophe, 1760.

[DACIER, Anne]. Le Plutus et les Nuées, comédies grecques, traduites en françois avec des Remarques \& un Examen de chaque Piece selon les regles du Theatre, par Mlle Lefevre, Paris, Thierry et Barbin, 1684.

[DACIER, André]. L'CEdipe et l'Électre de Sophocle, tragedies grecques traduites en François, avec des remarques, par André Dacier, Chez Claude Barbin sur le second Perron de la sainte Chapelle, Paris, 1692.

DaUmas, M. La tendresse amoureuse (XVI -XVIII siècles), Paris, PUF, 1997.

De Courville, X. Luigi Riccoboni dit Lélio, Genève-Paris, Droz, 3 vol., 1943-1958.

[De la Marche-Courmont, I.]. Réponse aux différens écrits publiés contre la comédie des Philosophes, ou Parallele des Nuées d'Aristophane, des Femmes Scavantes, du 
Méchant, \& des Philosophes, par M.D.L.M.C., s.l.n.d [1760], in Palissot, La Comédie des Philosophes [...], édition d'Olivier Ferret.

DE CAIGNY, F. Imitation, traduction et adaptation des tragédies de Sénèque aux XVI et XVII siècles, thèse de doctorat, université de Paris IV, 2004.

Dagen, J. L'Histoire de l'esprit humain dans la pensée française, de Fontenelle à Condorcet, Paris, Klincksieck, 1977.

Delmas, C. "L'unité du genre tragique au XVII ${ }^{\mathrm{e}}$ siècle ", Littératures classiques 16 (1992), p. 110-113.

Delaulne, F. Dictionnaire universel français et latin, dit Dictionnaire de Trévoux, Paris, 1721.

Delcourt, M. Étude sur les traductions des tragiques grecs et latins en France depuis la Renaissance, Bruxelles, Lamertin, 1925.

- La tradition des comiques anciens en France avant Molière, Paris, Droz, 1934

Denis, D. Le Parnasse galant. Institution d'une catégorie littéraire au XVII siècle, Paris, Champion, 2001.

[DIVo, A.]. Aristophanis comicorums principis comoediae undecim e graeco in latinum, ad verbum, translatae; Andrea Divo Justinopolitano interprete, Venetiis apud D. Jacob a Burgofrancho Papiensem, Mense Junio M.D.XXXVIII.

DüBner, F. Scholia graeca in Aristophanem, Paris, Firmin-Didot, 1877, reprint Hildesheim, Georg Olms Verlag, 1969, "Prolegomena de comøedia ", XI, p. XXVII, 46-55.

Dubos. Réflexions critiques sur la poésie et la peinture [1719], Paris, Mariette, 1733.

Duval, S. et Martinez, M. La satire, Paris, Armand Colin, collection « U ", 2000.

Falcomer, E. «Antifrancesismo letterario di primo Ottocento : l'inedito "Parallelo tra

i Poeti Classici Italiani ed i Francesi” di Carlo Vidua ", Franco-Italica, 1, 1992, p. 119-144.

FASsina, F. " Il Père Brumoy et il teatro greco. Una riflessione critiqua Sulla tragedia classica tra la "Querelle des Anciens et des Modernes" e l'Illuminismo ", Studi Francesi 158 (2009), p. 325-333.

Flamarion, É. «Que faire d'Aristophane quand on est jésuite en 1730 ? Ou le Théâtre des Grecs du P. Brumoy ", Cahiers du Groupe Interdisciplinaire de Théâtre Antique, "La tradition créatrice du théâtre antique. II. De Rome à nos jours »12, 1999.

-, Théâtre jésuite néo-latin et antiquité. Sur le Brutus de Charles Porée (1708), Rome, École française de Rome, 2002.

—, "Les "beautés de Racine” selon le P. Brumoy ", Littératures classiques 52 (automne 2004), p. 75-86.

Frantz, P. L'Esthétique du tableau dans le théâtre du XVIII siècle, PUF, 1998.

Fréron, É.-C. "Lettre X. Les Philosophes ", L'Année littéraire, t. IV [1760].

Frischlin, N. Aristophanes. Veteris comoediae princeps, poeta longe facetissimus o eloquentissimus, repurgatus a mendis, imitatione Plauti atque Terentii interpretatus, Francoforti ad Moenum, Joannes Spies, 1586.

Gallois, É. Le Théâtre des Grecs à l'usage des collèges et des gens du monde, 1840. 
Goguet, A.-Y. De l'origine des lois, des arts et des sciences et de leurs progrès chez les anciens peuples (1758), Paris (6éd.), 1820.

Grafton, A. Les origines tragiques de l'érudition : une histoire de la note en bas de page, Paris, 1998.

Greiner, F. et Ternaux, J.-C. (éd.). La politesse amoureuse de Marsile Ficin à Madeleine de Scudéry : idées, codes, représentations : actes du colloque international organisé à Reims du 17 au 19 novembre 1999, Franco-Italica, n 15-16, 1999.

Grosperrin, J.-Ph. «Résurrections princières de la tragédie grecque à la fin du règne de Louis XIV : L'Électre de Longepierre (1702) et l'Iphigénie en Tauride de Malézieu (1713)", Anabases 2 (2005), p. 115-145.

Hall, E. "Tragedy Personified ", in Kraus, Chr. et alii (éds.), Visualizing the Tragic. Drama, Myth, and Ritual in Greek Art and Literature. Essays in Honour of Froma Zeitlin, Oxford, 2007, p. 221-256.

La Harpe, J.-Fr. de. "De la tragédie ancienne ", in Lycée, ou Cours de littérature ancienne et moderne, éd. Dupont-Ledentu, 1825, t. 2, p. 255.

Hartog, Fr. Anciens, Modernes, Sauvages, Paris, Galaade, 2006.

Hédelin, Fr. (abbé d'Aubignac). La Pratique du théatre, Paris, Antoine de Sommaville, 1657.

Holtermann, M. Der deutsche Aristophanes. Die Rezeption eines politischen Dichters im 19. Jahrhundert, Göttingen, Vandenhoeck \& Ruprecht, 2004.

Houdar de La Motte, A. Second Discours à l'occasion de la tragédie de Romulus, dans Euvres de théâtre. Avec plusieurs discours sur la tragédie, Paris, Dupuis, 1730.

Jombert, Ch.-A. Catalogue de l'ouvre de Ch. Nic. Cochin fils, Paris, 1770.

Lafitau, Fr. Mours des Sauvages américains comparées aux mours des premiers temps (Paris, 1723), E. H. Lemay (éd.), Paris, 1983.

Lafleur, R.A. "Horace and Onomasti Komodein : The Law of Satire», Aufstieg und Niedergang der römischen Welt, II, 31, 3, Berlin-New York, 1981, p. 1790-1826.

Lechevalier, C. L'Invention d'une Origine. Traduire Eschyle en France de Lefranc de Pompignan à Mazon : Le Prométhée enchaîné, Paris, Champion, 2007.

[Le Loyer, P.]. La Néphélococugie ou La nuée des cocus: première adaptation des "Oiseaux » d'Aristophane en français, par Pierre LE LOYER ; édition critique préparée par M. Doe et K. Cameron, Genève, Droz, 2004.

LÉvi-STrauss, Cl. "Jean-Jacques Rousseau, fondateur des sciences de l'homme ", Anthropologie structurale deux, Paris, Plon, 1996 (1973).

Marmontel, J.-Fr. "Satyre ", in Supplément à L'Encyclopédie, t. IV, Amsterdam, M. M. Rey, 1777, p. 743. Le texte est repris dans les Éléments de littérature (Euvres complètes de M. Marmontel [...], 17 vol., Paris, Née de la Rochelle, 1787, t. $\mathrm{V}-\mathrm{X})$.

Mellot, J.-D. et Queval, É. Répertoire d'imprimeurs-libraires, XVI -XVIII siècles, nouvelle édition, Paris, BnF, 2004.

La Mesnardière. La Poétique, Paris, A. de Sommaville, 1640. 
Montagnier, J.-P. Un mécène musicien : Philippe d'Orléans, Régent, Paris, Zurfluh, 1996.

Ferret, O. Palissot, La Comédie des Philosophes et autres textes réunis, présentés et annotés par Olivier Ferret, Saint-Étienne, Publications de l'université de SaintÉtienne, 2002.

NAudeIX, L. «Les ombres dans la tragédie en musique (1673-1764) », dans Dramaturgies de l'ombre, Fr. Lavocat et Fr. Lecercle éd., Presses de l'université de Rouen, 2005, p. 247-261.

Palissot de Montenoy, Ch. «Dialogues Historiques et critiques. Second dialogue. Aristophane, \& le Pere Brumoy ", Théâtre et Euvres diverses, 3 vol, Londres, Paris, Duchesne, t. II, 1763, p. 290-296.

Pelous, J.-M. Amour précieux, amour galant (1654-1675). Essai sur la représentation de l'amour dans la littérature et la société mondaines, Paris, Klincksieck, 1980.

PiAnA, R. La réception d'Aristophane en France de Palissot à Vitez (1782-1962), thèse de l'université de Paris VIII, 2005.

Poinsinet de Sivry, L. Théâtre d'Aristophane, traduit en français partie en vers, partie en prose, avec les fragments de Ménandre et de Philémon, 4 vol., Paris, Didot jeune et Barrois aîné, 1784.

Polet, J.-C. (sous la dir. de). Patrimoine littéraire européen : anthologie en langue française, de Boeck Université, Bruxelles, 2000.

POMARÈDE, V. www.musagora.education.fr/muses/musesfr/icone.htm, reprenant un article de www.louvre.edu (consulté le 11/02/09), 2009.

Rapin, R. Réflexions sur la poétique de ce temps, éd. E. Dubois, Genève, Droz, 1970.

Quinault. Atys, tragédie en musique, Paris, Ballard, 1676, n.p.

Riccoboni, L. Histoire du Théâtre Italien, depuis la décadence de la Comedie Latine, à Paris, chez André Cailleau, 1730.

Rohвеск, J. "La philosophie de l'histoire chez Antoine-Yves Goguet : chronologie biblique et progrès historique ", Dix-huitième siècle 34 (2002), p. 257-266.

Ronsard, P. de. Euvres complètes. I; édition établie, présentée et annotée par J. CéArD, D. MÉnager et M. Simonin, 1991.

Rotrou, J. Iphigénie, V, 3-4, éd. A. Riffaud, Théâtre complet. 2, Paris, stfm, 1999.

Rousseau, J.-J. Discours sur l'origine, et les fondements de l'inégalité parmi les hommes (1755), Écrits politiques, Pléiade/Gallimard, Paris, 1964.

SAÏD, S. ; BieT, C. "L'enjeu des notes. Les traductions de l'Antigone de Sophocle au XVIII siècle ", Poétique 15 (1985), p. 155-169.

SChlenoff, N. Ingres, cahiers littéraires inédits, Paris, PuF, 1956.

Terrasson, H. Génie du théatre grec primitif ou Essai d'imitation d'Eschyle en vers français, Marseille, Ricard et Paris, Delaunay, 1817.

Therien, G. " La description du Sauvage par les Jésuites au début du XVII ${ }^{\mathrm{e}}$ siècle : de l'ethnologie à l'ethnodoxie ", Studies in Religion 23 (1994), p. 279-291.

Trivero, P. " Luigi Riccoboni, detto Lelio, non solo attore ", Franco-Italica, 1, 1992, p. 101-118. 
VAlentin, J.-M. « "Un système [...] faux [...], mais d'où résultent de si grandes beautés". Tragédie, tragique et destin dans le drame de tradition catholique : le Théâtre des Grecs de Pierre Brumoy s.j. ", in L'École, la ville, la cour, Paris, Klincksieck, 2004, p. 173-191.

VEGA, G. DE LA. Commentarios reales que tratan del origen de los Incas, Lisbonne (traduction française par Pradelle-Beaudoin, Paris, 1633).

VIALA, A. La France galante. Essai historique sur une catégorie culturelle, de ses origines jusqu'à la Révolution, Paris, PUf, 2008.

Vialleton, J.-Y. "Une catégorie "mineure" de l'esthétique théâtrale au XVII e siècle : la magnificence ", Littératures classiques 51 (automne 2004), p. 233-251.

Voltaire. Discours sur la tragédie, en tête de Brutus, in Euvres complètes, Voltaire Foundation, Oxford, 1998, t. 5.

Voltaire. Lettres sur Edipe [1719], in CEuvres complètes, Paris, Garnier Frères, 1877, Théâtre, t. I. 